JURNAL HUMANIORA

TEKNOLOGI

Vol. II No.I; Oktober 2016

\title{
ANALISIS BEBAN KERJA \\ DENGAN MENGGUNAKAN METODE SWAT
}

\author{
ADHIELA NOER SYAIEF \\ Jurusan Mesin Otomotif, Politeknik Negeri Tanah Laut \\ Jl. A. Yani, km 06, Ds. Panggung, kec. Pelaihari, Kab. Tanah Laut, Kalimantan Selatan
}

\begin{abstract}
Abstrak
Pengukuran beban kerja adalah salah satu faktor yang dibutuhkan oleh perusahaan. Karena dengan melakukan pengukuran beban kerja, perusahaan dapat mengetahui beban kerja yang diizinkan sehingga dapat memperlancar efektifitas pekerja dan perusahaan. Salah satu metode yang digunakan untuk mengetahui beban kerja adalah dengan melakukan analisis SWAT.

Analisis ini dilakukan di PT Berjaya Sekawanindo yang merupakan industri manufaktur yang bergerak di bidang pengalengan, khususnya pengalengan buah dan sayuran. Pengamatan dilakukan pada bagian produksi, dimana pekerjanya dituntut untuk dapat bergerak cepat dalam tugas proses produksinya yang rata-rata dikerjakan secara manual. Analisis ini dilakukan dengan cara pengamatan dan wawancara secara langsung dengan pekerja bagian produksi, melakukan pengukuran dengan cara pengambilan data hasil pengurutan kartu SWAT pada lima pekerja bagian produksi, analisis data dengan mengolah hasil pengurutan kartu SWAT ke dalam program Main SWAT lalu dilakukan pengkonversian antara hasil komputer dengan pekerjaan yang dilakukan, dan pengambilan kesimpulan dengan mengkonversikan antara nilai SWAT Rescaled dengan pekerjaan.

Hasil akhir dari analisis ini memberikan gambaran mengenai beban kerja yang dirasakan oleh pekerja bagian produksi. Hasil rata-rata beban kerja yaitu orang pertama diperoleh nilai rescaled rata-rata 49,2\%, orang kedua diperoleh nilai rescaled rata-rata 42,32\%, orang ketiga diperoleh nilai rescaled rata-rata 55,75\%, orang keempat diperoleh nilai rescaled rata-rata 48,07\%, dan orang kelima diperoleh nilai rescaled rata-rata 47,27\%. Sehingga dari keseluruhan nilai rescaled dari lima pekerja dapat diambil rata-rata yaitu 48,52\%. Dari nilai tersebut dapat disimpulkan bahwa ratarata setiap pekerja bagian produksi merasa terbebani dengan pekerjaannya.
\end{abstract}

Kata kunci: beban kerja, metode subjective workload, Main SWAT software

\section{PENDAHULUAN}

Pengukuran beban kerja merupakan salah satu faktor yang dibutuhkan oleh perusahaan untuk mengetahui beban kerja dari para pekerjanya. Karena pekerja merupakan salah satu faktor penting dalam proses yang mempengaruhi mutu dan produk perusahaan tersebut. Berdasarkan hasil pengamatan di PT Berjaya Sekawanindo 
perusahaan manufaktur yang bergerak di bidang pengalengan buah dan sayuran, pekerja pada bagian produksi dituntut untuk dapat bergerak cepat dalam memenuhi tuntutan target produksi pengalengan buah atau sayuran setiap harinya.

Dengan menggunakan analisis SWAT, perusahaan dapat mengetahui apakah para pekerjanya merasa terbebani atau tidak dengan tugas pekerjaannya. Tujuan yang ingin dicapai dalam analisis ini adalah sebagai berikut: (1) penerapan analisis SWAT; (2) menghitung nilai rescaled rata-rata setiap pekerja; (3) mengambil kesimpulan apakah setiap pekerja merasa terbebani atau tidak dengan pekerjaannya.

\section{METODE PENELITIAN}

Metode yang dipakai dalam pengambilan analisis ini adalah: (1) Pengamatan terhadap karyawan yaitu melakukan pengamatan kegiatan pekerja bagian produksi. (2) Wawancara yaitu memberikan pertanyaan-pertanyaan kepada pekerja bagian produksi mengenai tugas pekerjaannya. (3) Melakukan pengambilan data. Pengambilan data dengan cara meminta lima pekerja bagian produksi untuk melakukan pengurutan kartu SWAT. (4) Analisis data merupakan pengolahan hasil pengurutan kartu SWAT ke dalam program MAIN SWAT, lalu dilakukan pengkonversian antara hasil komputer dengan pekerjaan yang dilakukan. (5) Pengambilan kesimpulan. Antara nilai SWAT rescaled dengan pekerjaan dikonversikan kemudian dapat diambil kesimpulan apakah pekerja pada bagian produksi merasa terbebani atau tidak dengan pekerjaannya.

\section{HASIL DAN PEMBAHASAN}

Untuk dapat mengetahui beban kerja pekerja bagian produksi digunakan pengukuran beban kerja dengan metode SWAT (Subjective Workload Assessment Technique) Dalam penggunaan metode SWAT, performansi kerja manusia terdiri dari tiga dimensi ukuran beban kerja yaitu:

\section{- $\quad$ Time Load (T)}

Time Load ini adalah masalah yang tergantung pada jumlah waktu senggang yang tersedia. Besar kecilnya time load berhubungan dengan masalah tingkat kecepatan menyelesaikan pekerjaan dan batasan waktu yang tersedia dalam penyelesaian pekerjaan tersebut. 
- Mental Effort (E)

Mental effort merupakan indikator kebutuhan akan perhatian (usaha dan upaya) yang dibutuhkan untuk menyelesaikan suatu tugas. Besar kecilnya mental effort load ini tergantung pada kompleksitas dari suatu pekerjaan.

- Psychological Stress Load (S)

Psychological Stress Load mengacu pada kondisi yang menyebabkan kebimbangan, frustasi, dan kekhawatiran. Besar kecilnya masalah ini tergantung dari faktor yang mempengaruhi performa kerja yang bisa berasal dari individu itu sendiri seperti motivasi, kelelahan, rasa takut, tingkat keahlian, atau dari lingkungannya.

Dari masing-masing dimensi di atas terdiri dari 3 ( tiga ) kategori rating, yaitu: Rendah (1), Menengah (2) dan Tinggi (3).

Penggunaan model SWAT mengharuskan kita melakukan dua tahapan pekerjaan yaitu :

\section{- Tahap Scale Development}

Di dalam Scale Development, subjek diminta untuk melakukan pengurutan kartu SWAT sebanyak 27 (dua puluh tujuh) kartu kombinasi dari ketiga variabel deskripsi (T, E, S) mulai dari yang dianggap paling rendah sampai yang tertinggi. Scale Development digunakan untuk memperoleh data dengan memperhatikan bagaimana cara mengkombinasikan dimensi-dimensi untuk menciptakan impresi dari masingmasing individu tentang beban kerja.

Dari percobaan pengurutan kartu SWAT diperoleh data sebagai berikut:

Tabel 1

Hasil Pengurutan Kartu SWAT

Operator: Suci

\begin{tabular}{|c|c|c|c|c|c|}
\hline Nomor & Abjad & Nomor & Abjad & Nomor & Abjad \\
\hline 1. & $\mathrm{~N}$ & 10. & $\mathrm{U}$ & 19. & $\mathrm{H}$ \\
2. & $\mathrm{~B}$ & 11. & $\mathrm{G}$ & 20. & $\mathrm{P}$ \\
3. & $\mathrm{~W}$ & 12. & $\mathrm{Z}$ & 21. & $\mathrm{D}$ \\
4. & $\mathrm{~J}$ & 13. & $\mathrm{E}$ & 22. & $\mathrm{Y}$ \\
5. & $\mathrm{C}$ & 14. & $\mathrm{~V}$ & 23. & $\mathrm{~A}$ \\
6. & $\mathrm{~F}$ & 15. & $\mathrm{Q}$ & 24. & $\mathrm{O}$ \\
7. & $\mathrm{X}$ & 16. & $\mathrm{ZZ}$ & 25. & $\mathrm{~L}$ \\
8. & $\mathrm{~S}$ & 17. & $\mathrm{~K}$ & 26. & $\mathrm{~T}$ \\
9. & $\mathrm{M}$ & 18. & $\mathrm{R}$ & 27. & $\mathrm{I}$ \\
\hline
\end{tabular}


Tabel 2

Hasil Pengurutan Kartu SWAT

Nama: Rahmanto

\begin{tabular}{|c|c|c|c|c|c|}
\hline Nomor & Abjad & Nomor & Abjad & Nomor & Abjad \\
\hline 1. & $\mathrm{~N}$ & 10. & $\mathrm{~B}$ & 19. & $\mathrm{~W}$ \\
2. & $\mathrm{U}$ & 11. & $\mathrm{G}$ & 20. & $\mathrm{Z}$ \\
3. & $\mathrm{H}$ & 12. & $\mathrm{P}$ & 21. & $\mathrm{D}$ \\
4. & $\mathrm{~F}$ & 13. & $\mathrm{~J}$ & 22. & $\mathrm{C}$ \\
5. & $\mathrm{~V}$ & 14. & $\mathrm{Q}$ & 23. & $\mathrm{ZZ}$ \\
6. & $\mathrm{Y}$ & 15. & $\mathrm{~A}$ & 24. & $\mathrm{O}$ \\
7. & $\mathrm{X}$ & 16. & $\mathrm{~S}$ & 25. & $\mathrm{M}$ \\
8. & $\mathrm{~K}$ & 17. & $\mathrm{E}$ & 26. & $\mathrm{R}$ \\
9. & $\mathrm{~L}$ & 18. & $\mathrm{~T}$ & 27. & $\mathrm{I}$ \\
\hline
\end{tabular}

Tabel 3

Hasil Pengurutan Kartu SWAT

Nama: Rusti

\begin{tabular}{|c|c|c|c|c|c|}
\hline Nomor & Abjad & Nomor & Abjad & Nomor & Abjad \\
\hline 1. & N & 10. & U & 19. & H \\
2. & B & 11. & G & 20. & P \\
3. & W & 12. & Z & 21. & D \\
4. & F & 13. & V & 22. & Y \\
5. & J & 14. & Q & 23. & A \\
6. & C & 15. & ZZ & 24. & O \\
7. & X & 16. & K & 25. & I \\
8. & S & 17. & E & 26. & T \\
9. & M & 18. & R & 27. & L \\
\hline
\end{tabular}

Tabel 4

Hasil Pengukuran Kartu SWAT

Nama: Supriyati

\begin{tabular}{|c|c|c|c|c|c|}
\hline Nomor & Abjad & Nomor & Abjad & Nomor & Abjad \\
\hline 1. & $\mathrm{~N}$ & 10. & $\mathrm{U}$ & 19. & $\mathrm{H}$ \\
2. & $\mathrm{~B}$ & 11. & $\mathrm{G}$ & 20. & $\mathrm{P}$ \\
3. & $\mathrm{~W}$ & 12. & $\mathrm{Z}$ & 21. & $\mathrm{D}$ \\
4. & $\mathrm{~F}$ & 13. & $\mathrm{~V}$ & 22. & $\mathrm{Y}$ \\
5. & $\mathrm{~J}$ & 14. & $\mathrm{Q}$ & 23. & $\mathrm{~A}$ \\
6. & $\mathrm{C}$ & 15. & $\mathrm{Z}$ & 24. & $\mathrm{O}$ \\
7. & $\mathrm{X}$ & 16. & $\mathrm{~K}$ & 25. & $\mathrm{I}$ \\
8. & $\mathrm{~S}$ & 17. & $\mathrm{E}$ & 26. & $\mathrm{~T}$ \\
9. & $\mathrm{M}$ & 18. & $\mathrm{R}$ & 27. & $\mathrm{~L}$ \\
\hline
\end{tabular}


Tabel 5

Hasil Pengurutan Kartu SWAT

Nama: Lisa

\begin{tabular}{|c|c|c|c|c|c|}
\hline Nomor & Abjad & Nomor & Abjad & Nomor & Abjad \\
\hline 1. & $\mathrm{~N}$ & 10. & $\mathrm{U}$ & 19. & $\mathrm{H}$ \\
2. & $\mathrm{~F}$ & 11. & $\mathrm{~V}$ & 20. & $\mathrm{Y}$ \\
3. & $\mathrm{X}$ & 12. & $\mathrm{~K}$ & 21. & $\mathrm{~L}$ \\
4. & $\mathrm{~B}$ & 13. & $\mathrm{G}$ & 22. & $\mathrm{P}$ \\
5. & $\mathrm{~J}$ & 14. & $\mathrm{Q}$ & 23. & $\mathrm{~A}$ \\
6. & $\mathrm{~S}$ & 15. & $\mathrm{E}$ & 24. & $\mathrm{~T}$ \\
7. & $\mathrm{~W}$ & 16. & $\mathrm{Z}$ & 25. & $\mathrm{D}$ \\
8. & $\mathrm{C}$ & 17. & $\mathrm{ZZ}$ & 26. & $\mathrm{O}$ \\
9. & $\mathrm{M}$ & 18. & $\mathrm{R}$ & 27. & $\mathrm{~L}$ \\
\hline
\end{tabular}

(Sumber: Hasil Pengurutan dari Responden)

\section{- Tahap Event Scoring}

Pada tahap ini ditanyakan komentar SWAT rating skala pekerjaan (skala 1 sampai dengan 3) untuk masing-masing variabel T, E, S dari masing-masing elemen pekerjaan atau dalam penyelesaian suatu pekerjaan. Kemudian kartu SWAT rating tersebut dicocokkan dengan hasil dari pengurutan kartu SWAT di dalam program Main SWAT untuk mengetahui nilai beban kerja dari masing-masing kombinasinya.

Pada tabel berikut menunjukkan hasil pengkonversian pengurutan kartu SWAT yang dilakukan karyawan pada saat mereka melakukan aktivitas produksi.

\section{Sebelum Perbaikan Lingkungan Kerja}

Tabel 6

Hasil Pengukuran SWAT

Nama: Suci

\begin{tabular}{|c|l|c|c|c|c|}
\hline \multirow{2}{*}{$\begin{array}{c}\text { Lokasi } \\
\text { Kerja }\end{array}$} & \multirow{2}{*}{$\begin{array}{c}\text { Deskripsi } \\
\text { Pekerjaan }\end{array}$} & \multicolumn{3}{|c|}{ SWAT } & \multirow{2}{*}{$\begin{array}{c}\text { SWAT } \\
\text { Rescaled }\end{array}$} \\
\cline { 3 - 6 } & T & E & S & \\
\hline $\begin{array}{c}\text { Ruang } \\
\text { Produksi }\end{array}$ & $\begin{array}{l}\text { Penyortiran } \\
\text { Bahan Baku }\end{array}$ & 2 & 2 & 3 & 36,8 \\
\hline & $\begin{array}{l}\text { Pemotongan } \\
\text { Bahan Baku }\end{array}$ & 2 & 2 & 3 & 49,1 \\
\hline & Bleaching & 2 & 2 & 2 & 49,3 \\
\hline & Sterilisasi & 2 & 3 & 2 & 61,6 \\
\hline
\end{tabular}


Tabel 7

Hasil Pengukuran SWAT

Nama: Rahmanto

\begin{tabular}{|c|l|c|c|c|c|}
\hline \multirow{2}{*}{$\begin{array}{c}\text { Lokasi } \\
\text { Kerja }\end{array}$} & \multirow{2}{*}{$\begin{array}{c}\text { Deskripsi } \\
\text { Pekerjaan }\end{array}$} & \multicolumn{3}{|c|}{ SWAT } & \multirow{2}{*}{$\begin{array}{c}\text { SWAT } \\
\text { Rescaled }\end{array}$} \\
\cline { 3 - 6 } & & T & E & S & \\
\hline $\begin{array}{c}\text { Ruang } \\
\text { Produksi }\end{array}$ & $\begin{array}{l}\text { Penyortiran } \\
\text { Bahan Baku }\end{array}$ & 1 & 2 & 2 & 46,2 \\
\hline & $\begin{array}{l}\text { Pemotongan } \\
\text { Bahan Baku }\end{array}$ & 2 & 3 & 1 & 26,9 \\
\hline & Bleaching & 1 & 2 & 2 & 46,2 \\
\hline & Sterilisasi & 2 & 2 & 2 & 50 \\
\hline
\end{tabular}

Tabel 8

Hasil Pengukuran SWAT

Nama: Rusti

\begin{tabular}{|c|l|c|c|c|c|}
\hline \multirow{2}{*}{$\begin{array}{c}\text { Lokasi } \\
\text { Kerja }\end{array}$} & \multirow{2}{*}{$\begin{array}{c}\text { Deskripsi } \\
\text { Pekerjaan }\end{array}$} & \multicolumn{3}{|c|}{ SWAT } & \multirow{2}{*}{$\begin{array}{c}\text { SWAT } \\
\text { Rescaled }\end{array}$} \\
\cline { 3 - 6 } & & T & E & S & \\
\hline $\begin{array}{c}\text { Ruang } \\
\text { Produksi }\end{array}$ & $\begin{array}{l}\text { Penyortiran } \\
\text { Bahan Baku }\end{array}$ & 2 & 2 & 3 & 49,2 \\
\hline & $\begin{array}{l}\text { Pemotongan } \\
\text { Bahan Baku }\end{array}$ & 2 & 2 & 3 & 49,2 \\
\hline & Bleaching & 3 & 2 & 2 & 50,8 \\
\hline & Sterilisasi & 3 & 1 & 3 & 73,8 \\
\hline
\end{tabular}

Nilai $S W A T$ Rescale $<45$ = beban kerja rendah/tidak terbebani

Nilai $S W A T$ Rescale $>45=$ beban kerja tinggi/terbebani 
Tabel 9

Hasil Pengukuran SWAT

Nama: Supriyati

\begin{tabular}{|c|l|c|c|c|c|}
\hline \multirow{2}{*}{$\begin{array}{c}\text { Lokasi } \\
\text { Kerja }\end{array}$} & \multirow{2}{*}{$\begin{array}{c}\text { Deskripsi } \\
\text { Pekerjaan }\end{array}$} & \multicolumn{3}{|c|}{ SWAT } & \multirow{2}{*}{$\begin{array}{c}\text { SWAT } \\
\text { Rescaled }\end{array}$} \\
\cline { 3 - 6 } & & T & E & S & \\
\hline $\begin{array}{c}\text { Ruang } \\
\text { Produksi }\end{array}$ & $\begin{array}{l}\text { Penyortiran } \\
\text { Bahan Baku }\end{array}$ & 2 & 2 & 1 & 46,2 \\
\hline & $\begin{array}{l}\text { Pemotongan } \\
\text { Bahan Baku }\end{array}$ & 2 & 3 & 2 & 61,5 \\
\hline & Bleaching & 2 & 2 & 3 & 53.8 \\
\hline & Sterilisasi & 1 & 3 & 3 & 30,8 \\
\hline
\end{tabular}

Tabel 10

Hasil Pengukuran SWAT

Nama: Lisa

\begin{tabular}{|c|c|c|c|c|}
\hline \multirow{2}{*}{$\begin{array}{l}\text { Lokasi } \\
\text { Kerja }\end{array}$} & \multirow{2}{*}{$\begin{array}{l}\text { Deskripsi } \\
\text { Pekerjaan }\end{array}$} & \multicolumn{2}{|c|}{ SWAT } & \multirow{2}{*}{$\begin{array}{c}\text { SWAT } \\
\text { Rescale } \\
\text { d }\end{array}$} \\
\hline & & $\mathrm{T} / \mathrm{E}$ & $\mathrm{S}$ & \\
\hline \multirow[t]{4}{*}{$\begin{array}{c}\text { Ruang } \\
\text { Produksi }\end{array}$} & $\begin{array}{l}\text { Penyortiran } \\
\text { Bahan Baku }\end{array}$ & \begin{tabular}{l|l}
2 & 1
\end{tabular} & 2 & 47,7 \\
\hline & $\begin{array}{l}\text { Pemotongan } \\
\text { Bahan Baku }\end{array}$ & \begin{tabular}{l|l}
2 & 2
\end{tabular} & 3 & 58,6 \\
\hline & Bleaching & \begin{tabular}{l|l}
1 & 3
\end{tabular} & 3 & 29,7 \\
\hline & Sterilisasi & \begin{tabular}{l|l}
2 & 3
\end{tabular} & 2 & 53,1 \\
\hline
\end{tabular}

(Sumber : Hasil Pengolahan Data)

Keterangan: T: Time, E: Effort, S: Stress

\section{Setelah Perbaikan Lingkungan Kerja}

Perbaikan kondisi fisik lingkungan kerja pada dasarnya adalah salah satu cara untuk meningkatkan kenyamanan bekerja karyawan pada PT Berjaya Sekawanindo. Pada tabel berikut akan ditunjukkan hasil konversi yang dilakukan bagian produksi dan bagian packing pada saat mereka melakukan aktifitas kerja, sesudah dilakukan perbaikan lingkungan kerja. 
Tabel 11

Hasil Pengukuran SWAT

Nama: Suci

\begin{tabular}{|c|l|c|c|c|c|}
\hline \multirow{2}{*}{$\begin{array}{c}\text { Lokasi } \\
\text { Kerja }\end{array}$} & \multirow{2}{*}{$\begin{array}{l}\text { Deskripsi } \\
\text { Pekerjaan }\end{array}$} & \multicolumn{3}{|c|}{ SWAT } & \multirow{2}{*}{$\begin{array}{c}\text { SWAT } \\
\text { Rescaled }\end{array}$} \\
\cline { 3 - 5 } & T & E & S & \\
\hline $\begin{array}{c}\text { Ruang } \\
\text { Produksi }\end{array}$ & $\begin{array}{l}\text { Penyortiran } \\
\text { Bahan Baku }\end{array}$ & 1 & 3 & 2 & 24,8 \\
\hline & $\begin{array}{l}\text { Pemotongan } \\
\text { Bahan Baku }\end{array}$ & 2 & 1 & 1 & 38,6 \\
\hline & Bleaching & 1 & 3 & 3 & 24,6 \\
\hline & Sterilisasi & 2 & 1 & 2 & 37,0 \\
\hline
\end{tabular}

Tabel 12

Hasil Pengukuran SWAT

Nama: Rahmanto

\begin{tabular}{|c|l|c|c|c|c|}
\hline \multirow{2}{*}{$\begin{array}{c}\text { Lokasi } \\
\text { Kerja }\end{array}$} & \multirow{2}{*}{$\begin{array}{c}\text { Deskripsi } \\
\text { Pekerjaan }\end{array}$} & \multicolumn{3}{|c|}{ SWAT } & \multirow{2}{*}{ SWAT } \\
\cline { 3 - 5 } & T & E & S & Rescaled \\
\hline $\begin{array}{c}\text { Ruang } \\
\text { Produksi }\end{array}$ & $\begin{array}{l}\text { Penyortiran } \\
\text { Bahan Baku }\end{array}$ & 2 & 3 & 1 & 26,9 \\
\hline & $\begin{array}{l}\text { Pemotongan } \\
\text { Bahan Baku }\end{array}$ & 1 & 3 & 1 & 23,1 \\
\hline & Bleaching & 1 & 2 & 1 & 11,5 \\
\hline & Sterilisasi & 1 & 2 & 2 & 46,2 \\
\hline
\end{tabular}

Tabel 13

Hasil Pengukuran SWAT

Nama: Rusti

\begin{tabular}{|c|l|c|c|c|c|}
\hline \multirow{2}{*}{$\begin{array}{c}\text { Lokasi } \\
\text { Kerja }\end{array}$} & $\begin{array}{l}\text { Deskripsi } \\
\text { Pekerjaan }\end{array}$ & \multicolumn{3}{|c|}{ SWAT } & \multicolumn{2}{|c|}{$\begin{array}{c}\text { SWAT } \\
\text { Rescaled }\end{array}$} \\
\cline { 3 - 6 } & T & E & S & \\
\hline $\begin{array}{c}\text { Ruang } \\
\text { Produksi }\end{array}$ & $\begin{array}{l}\text { Penyortiran } \\
\text { Bahan Baku }\end{array}$ & 1 & 3 & 2 & 25,4 \\
\hline & $\begin{array}{l}\text { Pemotongan } \\
\text { Bahan Baku }\end{array}$ & 1 & 3 & 1 & 26,2 \\
\hline & Bleaching & 2 & 1 & 2 & 37,7 \\
\hline & Sterilisasi & 2 & 3 & 1 & 63,1 \\
\hline
\end{tabular}


Tabel 14

Hasil Pengukuran SWAT

Nama: Supriyati

\begin{tabular}{|c|l|c|c|c|c|}
\hline \multirow{2}{*}{$\begin{array}{c}\text { Lokasi } \\
\text { Kerja }\end{array}$} & $\begin{array}{l}\text { Deskripsi } \\
\text { Pekerjaan }\end{array}$ & \multicolumn{3}{|c|}{ SWAT } & \multicolumn{2}{|c|}{$\begin{array}{c}\text { SWAT } \\
\text { Rescaled }\end{array}$} \\
\cline { 3 - 6 } & & T & E & S & \\
\hline $\begin{array}{c}\text { Ruang } \\
\text { Produksi }\end{array}$ & $\begin{array}{l}\text { Penyortiran } \\
\text { Bahan Baku }\end{array}$ & 1 & 2 & 2 & 15,4 \\
\hline & $\begin{array}{l}\text { Pemotongan } \\
\text { Bahan Baku }\end{array}$ & 2 & 1 & 3 & 42,3 \\
\hline & Bleaching & 2 & 2 & 2 & 50,0 \\
\hline & Sterilisasi & 1 & 3 & 2 & 26,9 \\
\hline
\end{tabular}

Tabel 15

Hasil Pengukuran SWAT

Nama: Lisa

\begin{tabular}{|c|l|c|c|c|c|}
\hline \multirow{2}{*}{$\begin{array}{c}\text { Lokasi } \\
\text { Kerja }\end{array}$} & $\begin{array}{c}\text { Deskripsi } \\
\text { Pekerjaan }\end{array}$ & \multicolumn{3}{|c|}{ SWAT } & \multicolumn{2}{|c|}{$\begin{array}{c}\text { SWAT } \\
\text { Rescaled }\end{array}$} \\
\cline { 3 - 5 } & & T & E & S & \\
\hline $\begin{array}{c}\text { Ruang } \\
\text { Produksi }\end{array}$ & $\begin{array}{l}\text { Penyortiran } \\
\text { Bahan Baku }\end{array}$ & 1 & 2 & 3 & 18,2 \\
\hline & $\begin{array}{l}\text { Pemotongan } \\
\text { Bahan Baku }\end{array}$ & 1 & 2 & 2 & 18,5 \\
\hline & Bleaching & 1 & 3 & 1 & 26,4 \\
\hline & Sterilisasi & 1 & 3 & 2 & 22,4 \\
\hline
\end{tabular}

(Sumber : Hasil Pengolahan Data)

Keterangan: T: Time, E: Effort, S: Stress

Nilai SWAT Rescale $<45$ = beban kerja rendah / tidak terbebani

Nilai SWAT Rescale $>45$ = beban kerja tinggi / terbebani

Penilaian ini berdasar pada pengurutan 27 kartu yang benar menurut pembuat software SWAT, apabila skor skala menunjukkan 50 maka berada tepat pada ambang batas antara mampu menanggung beban pekerjaan dan tidak. Untuk itu diberikan 
kebijakan sebelum berada pada posisi ini, maka diberikan kelonggaran (all=10\%) agar tidak sampai pada titik kritis. Kebijakan ini dilakukan karena nilai SWAT rating antara 0-100 dan titik tengah 50. Sehingga kesimpulan scale maksimum adalah $50-(10 \% \mathrm{x}$ $50)=45$. Bila SWAT ratingnya berada lebih dari 45 maka kesimpulan yang bisa diambil adalah beban kerjanya tinggi, artinya operator akan cenderung melakukan kesalahan.

Setelah melihat hasil pengurutan kartu yang dilakukan oleh pekerja dibagian produksi, maka dapat diketahui kinerja pada setiap pekerja mempunyai nilai SWAT Rescaled rata-rata diatas 45 pada setiap elemen kerja yang mereka dilakukan, dengan demikian dapat disimpulkan bahwa rata-rata dalam proses pekerjaannya, karyawan merasa tidak nyaman. Tapi setelah dilakukan perbaikan kondisi lingkungan kerja, SWAT Rescaled rata-rata dibawah 45 pada rata-rata setiap elemen kerja yang mereka lakukan, dengan demikian dapat disimpulkan bahwa setiap proses pekerjaan mereka merasa tidak terbebani.

\section{KESIMPULAN}

Dari nilai SWAT rescaled 5 pekerja bagian produksi setelah dilakukan perbaikan mengalami peningkatan dan dapat diketahui bahwa nilai SWAT rescaled ratarata kurang dari 45 sehingga pekerja yang melakukan pekerjaan tidak merasa terbebani dan setelah dilakukan perbaikan, pekerja bagian produksi PT Berjaya Sekawanindo dapat melakukan pekerjaannya dengan nyaman dan optimal.

\section{DAFTAR PUSTAKA}

Laboratorium Ergonomi. 2007. Modul Praktikum Ergonomi. Malang: ITN.

Nurmianto, Eko. 2004. Ergonomi. Surabaya: Guna Widya.

Soebroto, Wignyo Sritomo, 1995. Ergonomi Studi Gerak dan Waktu. Surabaya: Institut Teknologi Sepuluh November. 